\title{
Dose-response curve to salbutamol during acute and chronic treatment with formoterol in COPD
}

This article was published in the following Dove Press journal:

International Journal of COPD

8 July 2011

Number of times this article has been viewed

\author{
Giuseppe Emanuele La \\ Pianal \\ Luciano Corda ${ }^{2}$ \\ Enrica Bertella' \\ Luigi Taranto Montemurro' \\ Laura Pini' \\ Claudio Tantucci ${ }^{1}$ \\ 'Cattedra di Malattie dell'Apparato \\ Respiratorio, Università di Brescia, \\ 2Prima Divisione di Medicina Interna, \\ Spedali Civili, Brescia, Italy
}

Background: Use of short-acting $\beta_{2}$-agonists in chronic obstructive pulmonary disease (COPD) during treatment with long-acting $\beta_{2}$-agonists is recommended as needed, but its effectiveness is unclear. The purpose of this study was to assess the additional bronchodilating effect of increasing doses of salbutamol during acute and chronic treatment with formoterol in patients with COPD.

Methods: Ten patients with COPD underwent a dose-response curve to salbutamol (until $800 \mu \mathrm{g}$ of cumulative dose) after a 1-week washout (baseline), 8 hours after the first administration of formoterol $12 \mu \mathrm{g}$ (day 1), and after a 12-week and 24-week period of treatment with formoterol (12 $\mu \mathrm{g}$ twice daily by dry powder inhaler). Peak expiratory flow, forced expiratory volume in one second $\left(\mathrm{FEV}_{1}\right)$, forced vital capacity, and inspiratory capacity were measured at the different periods of treatment and at different steps of the dose-response curve.

Results: Despite acute or chronic administration of formoterol, maximal values of peak expiratory flow, $\mathrm{FEV}_{1}$, and forced vital capacity after $800 \mu \mathrm{g}$ of salbutamol were unchanged compared with baseline. The baseline $\mathrm{FEV}_{1}$ dose-response curve was steeper than that at day 1 , week 12 , or week $24(P<0.0001)$. Within each dose-response curve, $\mathrm{FEV}_{1}$ was different only at baseline and at day $1(P<0.001)$, when $\mathrm{FEV}_{1}$ was still greater at $800 \mu \mathrm{g}$ than at $0 \mu \mathrm{g}(P<0.02)$. In contrast, the forced vital capacity dose-response curves were similar at the different periods, while within each dose-response curve, forced vital capacity was different in all instances $(P<0.001)$, always being higher at $800 \mu \mathrm{g}$ than at $0 \mu \mathrm{g}(P<0.05)$.

Conclusion: In patients with stable COPD, the maximal effect of salbutamol on peak expiratory flow, $\mathrm{FEV}_{1}$, and forced vital capacity was unchanged after either acute or chronic treatment with formoterol. With increasing doses of salbutamol, FEV increased only after acute administration of formoterol. Forced vital capacity also significantly improved during long-term treatment with formoterol.

Keywords: chronic obstructive pulmonary disease, salbutamol, formoterol, long-acting $\beta_{2}$-agonists

\section{Introduction}

The effect of increasing doses of short-acting $\beta_{2}$-agonists (SABA) in patients with stable COPD during long-term treatment with long-acting $\beta_{2}$-agonists (LABA) is presently unknown. The current guidelines recommend treating COPD patients with bronchodilating drugs, ${ }^{1}$ and among them, LABA are widely used. ${ }^{2-4}$ Indeed, although changes in forced expiratory volume in one second $\left(\mathrm{FEV}_{1}\right)$ after acute or chronic administration of bronchodilating agents are usually scarce in COPD, other volume parameters, such as inspiratory capacity and forced vital capacity, must be taken into account to assess the effectiveness of therapy with bronchodilators in these patients. ${ }^{5}$ During regular LABA
Correspondence: Luciano Corda Prima Divisione di Medicina, Spedali Civili, P le Spedali Civili I, Brescia 25I23, Italy

Tel +390303995237

$\mathrm{Fax}+390303996011$

Email luciano.corda@spedalicivili.brescia.it 
treatment, if the airflow obstruction increases abruptly, a therapeutic option is to add SABA as rescue medication, trying to achieve rapid and effective control of airway obstruction and related symptoms. However, regular treatment with LABA could reduce the bronchodilatory response to repeated doses of SABA because of occupation or potential downregulation of $\beta_{2}$ adrenoreceptors. ${ }^{6}$ Cazzola et al performed a placebocontrolled study of the effect of acute pretreatment with LABA (salmeterol, formoterol, or oxitropium via metered dose inhaler) on the bronchodilating response to incremental doses of inhaled salbutamol in a cohort of patients with COPD and marked reversibility of airway obstruction, as assessed by acute $\mathrm{FEV}_{1}$ change. ${ }^{7}$ All long-acting bronchodilators elicited a significant increase in $\mathrm{FEV}_{1}$, and a significant dose-dependent increment in $\mathrm{FEV}_{1}$ was seen after salbutamol administration, suggesting that salbutamol is useful as a "rescue agent" in COPD when using long-acting bronchodilators, including LABA. ${ }^{7}$ However, this study did not address the relevant clinical question of whether or not similar results would be obtained after long-term use of LABA in patients with COPD. ${ }^{8}$ Therefore, the aim of the present study was to assess if the main indices of airway obstruction are positively affected in the dose-response curve to inhaled salbutamol not only after acute but also after chronic treatment with formoterol, a longacting pure $\beta_{2}$-agonist, in patients with stable COPD.

\section{Methods}

Approval of our ethics committee was obtained prior to embarking on this research. After providing their written informed consent, 15 consecutive patients were enrolled, suffering from COPD with moderate-to-severe airway obstruction, defined according to the following criteria: smoking history of more than 20 pack-years and/or presence of other known risk factors for COPD (frequent respiratory tract infections in childhood, chronic cough and phlegm, occupational exposures, indoor pollutants by biomass fuel, $\alpha 1$-antitrypsin deficiency); baseline $\mathrm{FEV}_{1} /$ vital capacity ratio $<5$ th percentile of lower limit of normal, corresponding to $\mathrm{FEV}_{1} /$ vital capacity ratio $<88 \%$ predicted $^{9,10}$ and a baseline $\mathrm{FEV}_{1}<80 \%$ predicted and $>30 \%$ predicted; increase of $\mathrm{FEV}_{1}<10 \%$ of predicted and $200 \mathrm{~mL}$ after $400 \mu \mathrm{g}$ of inhaled salbutamol; 9,10 absence of history of bronchial asthma, allergic rhinitis or atopy; and no concomitant restrictive lung or chest wall disorders. To be eligible for the study, patients had to be in a stable condition without any symptoms or treatment changes in the 4 weeks prior to the study, have had no exacerbations in the preceding 12 weeks, and be able to perform forced expiratory maneuvers adequately. No patient was suffering from known cardiovascular disease, a neuromuscular disorder, or any metabolic or hormonal alterations. All patients treated with inhaled corticosteroids had to stop these drugs at least 4 weeks before the beginning of the study. No other concomitant drugs were allowed during the study, except for SABA as rescue medication. On the first day, patients were asked to withdraw any LABA for one week and SABA for 12 hours before starting the study.

After the washout period, each patient performed spirometry with a maximal flow/volume curve, underwent measurement of DLCO (diffusing capacity of the lung for carbon monoxide) and lung volumes by the multibreath helium dilution method, and assessment of tidal expiratory flow limitation with the negative expiratory pressure technique. ${ }^{11}$ Afterwards, they underwent a dose-response curve to salbutamol, performing a series of spirometric maneuvers with maximal expiratory flow/volume curve 20 minutes after inhalation (metered dose inhaler + spacer) of subsequent doses of salbutamol ( $0 \mu \mathrm{g}, 100 \mu \mathrm{g}, 100 \mu \mathrm{g}, 200 \mu \mathrm{g}, 400 \mu \mathrm{g})$, reaching a cumulative dose of $800 \mu \mathrm{g}$ at baseline period. Treatment with formoterol dry powder inhaler $12 \mu \mathrm{g}$ twice daily was then prescribed, starting from the following morning with no other inhaled drug. In all patients, the doseresponse curve to salbutamol as previously described was repeated on the first day of treatment, and after 12 weeks and 24 weeks. These tests were always performed eight hours after the morning dose of formoterol. The maximal cumulative dose of salbutamol of $800 \mu \mathrm{g}$ was chosen to avoid the potentially dangerous effects of acute $\beta_{2}$ stimulation on cardiac function elicited by higher doses of the drug and because it is highly improbable that patients with COPD would use more than eight puffs of salbutamol as a single rescue dose in real life. On each occasion, inspiratory capacity was measured prior to the maximal expiratory flowvolume curve by inspiring from end expiratory lung volume to total lung capacity. The predicted inspiratory capacity values were those proposed by Tantucci et al. ${ }^{12}$

Adherence to treatment with formoterol was assessed at each period by checking the dose counter of the dry powder inhaler. Monitoring of side effects was performed by evaluating heart rate and blood pressure values before and after each dose of salbutamol.

\section{Spirometry}

A computerized water-sealed light-bell Stead-Wells spirometer (Biomedin, Padua, Italy) was used and the operator was assisted during the test with software able to verify both acceptability and repeatability of spirometric maneuvers online. 
All measurements were made in accordance with the guidelines of the American Thoracic Society, ${ }^{9,10}$ with the subjects in the sitting position, wearing a nose clip. During the study, the neck was held in a fixed neutral position to avoid changes associated with different neck positions, and no inspiratory pause was allowed at total lung capacity before performing the forced expiratory maneuver. We adopted the reference values for pulmonary function parameters proposed by Quanjer et al. ${ }^{13}$

\section{Negative expiratory pressure test}

The patients breathed quietly, wearing a nose clip, through a mouthpiece and a heated pneumotachograph (Series 3700; Hans Rudolph, Kansas City, MO) connected to a differential pressure transducer (Raytech DP55 $\pm 3 \mathrm{~cm} \mathrm{H}_{2} \mathrm{O}$; Raytech Instruments, Vancouver, Canada) to measure flow. Pressure was measured at the mouth by a differential pressure transducer (Raytech DP55 $\pm 100 \mathrm{~cm} \mathrm{H}_{2} \mathrm{O}$ ). The pneumotachograph was assembled in series with a Venturi device that created a negative pressure in the circuit which could be precisely fixed. This technique is described fully elsewhere. ${ }^{5,11}$

\section{Statistical analysis}

The sample size of 15 provided a statistical power of $90 \%$ $(\beta=0.10)$ to detect the smallest clinically relevant mean difference of $140 \mathrm{~mL}$ of $\mathrm{FEV}_{1}{ }^{14}$ with a standard deviation of the differences in response to bronchodilators of $140 \mathrm{~mL}$ of FEV found in our laboratory at $5 \%$ of significance level $(\beta=0.05)$ for a paired $t$-test. Average data of the variables of interest were compared by multifactorial analysis of variance to establish any significant overall effect among the four periods. If significant, Sheffé multiple range test was used to identify which differences were significant. Analysis of variance for repeated measures with the Bonferroni correction was performed to analyze and compare data within the dose-response curve of each period (baseline, day 1, week 12, week 24). A $P$ value $<0.05$ was considered to be statistically significant. Data are expressed as means \pm standard deviation. Statistical analysis was performed using the Stat View software package (Stat View; SAS Institute Inc, Cary, NC).

\section{Results}

Five of the 15 patients dropped out (four because of noncompliance with LABA and one because of an exacerbation at week 10), and 10 (including seven males) successfully completed the study. Anthropometric and functional data are shown in Table 1. Three patients were flow-limited at rest during tidal expiration in the sitting position with an inspiratory capacity of $56.6 \% \pm 12.0 \%$ predicted, while seven patients were not flow-limited and had a normal inspiratory capacity of $94.0 \% \pm 7.8 \%$ predicted. All patients were former smokers (range 20-54 pack-years). All patients had quit smoking at least 1 year before enrolling in this study and no patient smoked before the pulmonary function test. No changes in smoking habit were observed and no exacerbation was reported among patients who completed the protocol.

Mean values for $\mathrm{FEV}_{1}$, forced vital capacity, peak expiratory flow, $\mathrm{FEV}_{1}$ /forced vital capacity, and inspiratory capacity, and the response to subsequent cumulative doses of salbutamol at baseline, day 1, week 12, and week 24 periods are shown in Table 2. The $\mathrm{FEV}_{1}$ and forced vital capacity dose-response curves to salbutamol at the different periods are shown in Figure 1.

Table I Anthropometric and functional data of patients who were enrolled $(n=15)$ and who completed the study $(n=10)$

\begin{tabular}{|c|c|c|c|c|}
\hline & $(n=15)$ & & $(n=10)$ & \\
\hline Gender (M/F) & $\mathrm{IIM} / 4 \mathrm{~F}$ & & $7 \mathrm{M} / 3 \mathrm{~F}$ & \\
\hline Age (yrs) & $63.4 \pm 10.6$ & & $61.7 \pm 10.4$ & \\
\hline Body weight $(\mathrm{kg})$ & $69.5 \pm 13.0$ & & $70.5 \pm 12.2$ & \\
\hline Height (m) & $1.63 \pm 0.1$ & & $\mathrm{I} .62 \pm 0 . \mathrm{I}$ & \\
\hline \multirow[t]{2}{*}{ BMI $\left(\mathrm{kg} / \mathrm{m}^{2}\right)$} & $26.1 \pm 4.0$ & & $26.7 \pm 4.0$ & \\
\hline & Absolute values & (\% predicted) & Absolute values & (\% predicted) \\
\hline $\mathrm{FEV}_{1} / \mathrm{VC}$ & $43.7 \% \pm 11.1 \%$ & $57.5 \pm 15.2$ & $40.9 \% \pm 11.0 \%$ & $53.5 \pm 14.7$ \\
\hline $\mathrm{FEV}_{1}$ & $1.36 \pm 0.5 \mathrm{I} \mathrm{L}$ & $53.3 \pm 16.5$ & $1.29 \pm 0.53 \mathrm{~L}$ & $50.4 \pm 16.9$ \\
\hline FVC & $2.66 \pm 0.69 \mathrm{~L}$ & $83.4 \pm 16.1$ & $2.62 \pm 0.8 \mathrm{IL}$ & $82.5 \pm 19.6$ \\
\hline IC & $2.29 \pm 0.70 \mathrm{~L}$ & $81.8 \pm 12.6$ & $2.24 \pm 0.78 \mathrm{~L}$ & $82.8 \pm 20.2$ \\
\hline TLC & $5.49 \pm 0.93 \mathrm{~L}$ & $98.8 \pm 17.9$ & $5.76 \pm 0.95 \mathrm{~L}$ & $104.4 \pm 15.8$ \\
\hline FRC & $3.24 \pm 0.7 I \mathrm{~L}$ & $103.5 \pm 23.2$ & $3.42 \pm 0.75 \mathrm{~L}$ & $109.4 \pm 25.8$ \\
\hline RV & $2.46 \pm 0.62 \mathrm{~L}$ & $115.7 \pm 34.6$ & $2.59 \pm 0.66 \mathrm{~L}$ & $123.7 \pm 33.5$ \\
\hline DLCO & $12.24 \pm 4.93 \mathrm{~mL} / \mathrm{min} * \mathrm{mmHg}$ & $53.2 \pm 20.9$ & $12.8 \pm 5.32 \mathrm{~mL} / \mathrm{min} * \mathrm{mmHg}$ & $54.9 \pm 22.9$ \\
\hline
\end{tabular}

Note: Data are mean \pm standard deviation.

Abbreviations: BMI, body mass index; DLCO, diffusing capacity of the lung for carbon monoxide; FRC, functional residual capacity; FEV ${ }_{1}$, forced expiratory volume in one second; FVC, forced vital capacity; IC, inspiratory capacity; TLC, total lung capacity; VC, vital capacity; RV, residual volume. 
Table 2 Lung function parameters at baseline and at each period of treatment with formoterol for each cumulative dose of salbutamol

\begin{tabular}{|c|c|c|c|c|c|c|}
\hline Period & & $0 \mu \mathrm{g}$ & $100 \mu \mathrm{g}$ & $200 \mu \mathrm{g}$ & $400 \mu \mathrm{g}$ & $800 \mu \mathrm{g}$ \\
\hline \multirow[t]{6}{*}{ Baseline } & $\mathrm{FEV}_{1}$ & $50.4 \pm 16.9$ & $52.2 \pm 16.2$ & $54.4 \pm 17.1$ & $55.8 \pm 16.2$ & $58.2 \pm 16.8^{*}$ \\
\hline & FVC & $82.5 \pm 19.6$ & $85.3 \pm 18.8$ & $88.2 \pm 17.1$ & $90.3 \pm 16.93$ & $92.3 \pm 14.6^{*}$ \\
\hline & PEF & $55.6 \pm 13.3$ & $56.9 \pm 11.2$ & $58.8 \pm 11.7$ & $59.7 \pm 13.1$ & $60.0 \pm 13.4^{*}$ \\
\hline & $\mathrm{FEV}_{1} / \mathrm{FVC}(\%)$ & $48.6 \pm 9.2$ & $48.8 \pm 8.3$ & $50.4 \pm 9.2$ & $50.4 \pm 7.9$ & $50.9 \pm 9.4$ \\
\hline & IC & $82.8 \pm 20.2$ & $85.3 \pm 18.8$ & $88.2 \pm 17.1$ & $90.3 \pm 16.9$ & $91.3 \pm 14.6$ \\
\hline & IC (3 FL pts) & $56.6 \pm 12.8$ & $57.8 \pm 13.4$ & $61.6 \pm 9.3$ & $63.6 \pm 13.7$ & $67.4 \pm 13.1$ \\
\hline \multirow[t]{6}{*}{ Day $\left.\right|^{\S}$} & $\mathrm{FEV}_{1}$ & $55.2 \pm 16.8$ & $56.5 \pm 15.9$ & $58.1 \pm 15.4$ & $58.3 \pm 15.4$ & $58.7 \pm 14.6^{*}$ \\
\hline & FVC & $86.2 \pm 20.7$ & $88.8 \pm 19.2$ & $91.5 \pm 19.6$ & $92.1 \pm 18.4$ & $92.7 \pm 18.6^{*}$ \\
\hline & PEF & $59.1 \pm 14.9$ & $60.5 \pm 14.6$ & $61.4 \pm 13.8$ & $60.8 \pm 14.3$ & $62.2 \pm 12.4$ \\
\hline & $\mathrm{FEV}_{1} / \mathrm{FVC}(\%)$ & $51.2 \pm 7.7$ & $50.9 \pm 7.5$ & $50.7 \pm 7.8$ & $52 \pm 9.9$ & $51.9 \pm 9.0$ \\
\hline & IC & $86.2 \pm 20.7$ & $88.8 \pm 19.2$ & $91.5 \pm 19.7$ & $92.1 \pm 18.4$ & $91.7 \pm 18.7$ \\
\hline & IC (3 FL pts) & $58.9 \pm 10.3$ & $64.4 \pm 8.2$ & $65.8 \pm 6.7$ & $66.5 \pm 8.6$ & $67.5 \pm 7.2$ \\
\hline \multirow[t]{6}{*}{ Week $12^{\S}$} & $\mathrm{FEV}_{1}$ & $54.1 \pm 17.6$ & $54.5 \pm 17.0$ & $56.4 \pm 15.7$ & $56.4 \pm 15.7$ & $57.5 \pm 16.4$ \\
\hline & FVC & $85.2 \pm 18.3$ & $86.4 \pm 18$ & $87.2 \pm 15.8$ & $87.7 \pm 15.7$ & $90.0 \pm 14.8^{*}$ \\
\hline & PEF & $58.1 \pm 15.3$ & $60 \pm 12.8$ & $57.3 \pm 13.7$ & $57.7 \pm 13.7$ & $59.9 \pm 15.3$ \\
\hline & $\mathrm{FEV}_{1} / \mathrm{FVC}(\%)$ & $50.2 \pm 8.1$ & $50.4 \pm 8.9$ & $51.7 \pm 8.0$ & $51.1 \pm 7.9$ & $50.5 \pm 8.5$ \\
\hline & IC & $86.0 \pm 18.9$ & $86.9 \pm 18.6$ & $89.0 \pm 18.2$ & $89.8 \pm 16.9$ & $91.0 \pm 19.3$ \\
\hline & IC (3 FL pts) & $58.3 \pm 13.0$ & $60.7 \pm 14.9$ & $63.7 \pm 14.9$ & $64.6 \pm 10.9$ & $65.2 \pm 9.9$ \\
\hline \multirow[t]{6}{*}{ Week $24^{\S}$} & $\mathrm{FEV}_{1}$ & $55.3 \pm 18.6$ & $56.3 \pm 18.8$ & $57.3 \pm 18.2$ & $57.3 \pm 18.2$ & $58.1 \pm 18.7$ \\
\hline & FVC & $88.1 \pm 19.9$ & $88.5 \pm 20.9$ & $90.3 \pm 20.3$ & $90.7 \pm 20.8$ & $92.5 \pm 20.3^{*}$ \\
\hline & PEF & $57.5 \pm 16.1$ & $58.2 \pm 17.3$ & $58.1 \pm 15.6$ & $60.4 \pm 17.4$ & $60.6 \pm 16.6$ \\
\hline & $\mathrm{FEV}_{1} / \mathrm{FVC}(\%)$ & $50.6 \pm 8.3$ & $50.6 \pm 8.2$ & $51.3 \pm 8.1$ & $50.7 \pm 7.9$ & $50.3 \pm 8.3$ \\
\hline & IC & $88.1 \pm 19.5$ & $88.5 \pm 20.7$ & $90.3 \pm 20.7$ & $90.7 \pm 20.8$ & $92.5 \pm 20.4$ \\
\hline & IC (3 FL pts) & $56.4 \pm 9.2$ & $57.8 \pm 11.7$ & $60.8 \pm 12.4$ & $64.9 \pm 12.9$ & $64.7 \pm 12.9$ \\
\hline
\end{tabular}

Notes: Data are mean \pm standard deviation and expressed as \% predicted, except for $\mathrm{FEV} / \mathrm{FVC}$ ratio. $* P<0.05$ versus $0 \mu \mathrm{g}$; ${ }^{\S P}<0.00 \mathrm{I}$ versus baseline for $\mathrm{FEV}$. Abbreviations: BMI, body mass index; DLCO, diffusing capacity of the lung for carbon monoxide; FRC, functional residual capacity; FEV ${ }_{1}$, forced expiratory volume in one second; FVC, forced vital capacity; IC, inspiratory capacity; TLC, total lung capacity; VC, vital capacity; ICFL, flow limited at rest.

Following both acute and chronic administration of formoterol, $\mathrm{FEV}_{1}$ before salbutamol $(0 \mu \mathrm{g})$ was always higher when compared with baseline (day 1, week 12 and week 24 versus baseline, $P<0.01$, Figure 1 and Table 2).

At the different assessment periods, the dose-response curves were different for $\mathrm{FEV}_{1}(P<0.01)$, and almost significantly different for peak expiratory flow $(P=0.056)$, but this was not the case for forced vital capacity. In particular, the $\mathrm{FEV}_{1}$ dose-response curve at baseline was significantly steeper than those at day 1 , week 12, and week 24 $(P<0.0001$, Figure 1$)$.

Within each dose-response curve for salbutamol, $\mathrm{FEV}_{1}$ values were significantly different only at baseline and day $1(P<0.001)$ and peak expiratory flow values only at baseline $(P<0.001)$, while forced vital capacity values remained significantly different at all periods of the study $(P<0.001)$. In particular, $\mathrm{FEV}_{1}$ increased significantly between dose $0 \mu \mathrm{g}$ and dose $800 \mu \mathrm{g}$ of salbutamol both at baseline and at day $1(P<0.05)$, and peak expiratory flow only at baseline $(P<0.01)$. In contrast, forced vital capacity increased from dose $0 \mu \mathrm{g}$ to dose $800 \mu \mathrm{g}$ of salbutamol in all instances $(P<0.05$, Table 2$)$.
At each period of the study, the inspiratory capacity values showed no significant changes during incremental doses of salbutamol when all patients were included. This occurred because inspiratory capacity was normal and remained unchanged after bronchodilators in seven patients who were not flow-limited. However, if only three tidally flow-limited COPD patients were taken into account, a trend similar to that found for forced vital capacity was observed also for inspiratory capacity (Table 2).

\section{Discussion}

The main results of the study were: the maximal effect after the last dose of salbutamol on peak expiratory flow, $\mathrm{FEV}_{1}$, and forced vital capacity did not change compared with baseline at each period of treatment with formoterol; while the significant $\mathrm{FEV}_{1}$ increment occurring after salbutamol on top of the first dose of formoterol was lost during chronic treatment, a significant improvement in forced vital capacity was still observed during long-term treatment with formoterol, although always at the highest dose of salbutamol $(800 \mu \mathrm{g})$; and no changes in inspiratory capacity were found in any patient, but at least in those with baseline tidal 

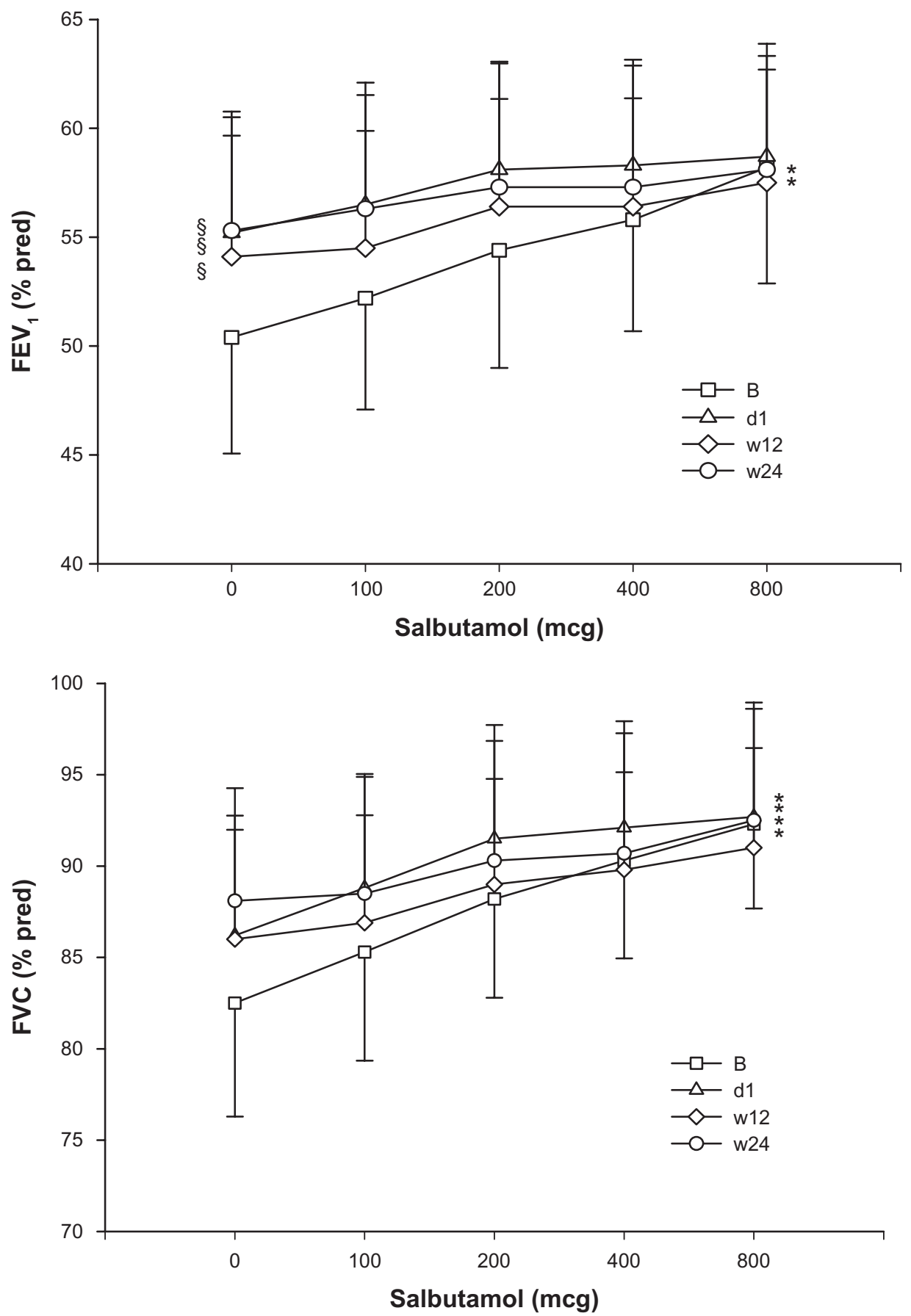

Figure I FEV and FVC are shown as \% predicted at baseline and at each period of treatment for each cumulative dose of salbutamol.

Notes: ${ }^{P} P<0.05$ versus $0 \mu \mathrm{g}$ for FEV, at $800 \mu \mathrm{g}$ at baseline and day I, and for FVC at $800 \mu \mathrm{g}$ at all periods; ${ }^{\circledR} P<0.00 \mathrm{I}$ versus baseline; symbols are means, bars are standard error of the mean.

Abbreviations: $\mathrm{FEV}_{1}$, forced expiratory volume in one second; FVC, forced vital capacity.

expiratory flow limitation and resting dynamic hyperinflation, changes similar to forced vital capacity were observed also for inspiratory capacity.

Our goal was to assess the bronchodilating effect elicited by acute SABA administration in patients with stable moderate-to-severe COPD during short-term and long-term treatment with LABA. Formoterol is a full LABA with a very rapid onset of bronchodilating action that lasts for about 12 hours due to its lipophilic properties. ${ }^{15}$ In COPD, prolonged administration of formoterol at a dosage of $12 \mu \mathrm{g}$ twice daily is associated with better $\mathrm{FEV}_{1}$ and peak expiratory flow values over time and significant improvement of clinical outcomes. ${ }^{16}$ However, the aim of this study was to measure functional changes and not clinical improvement. 
Inhaled SABA that induce bronchodilation in a few minutes and reach maximal effect after 20-30 minutes are usually the preferred rescue bronchodilators for the treatment of either intermittent or worsening symptoms in patients with COPD. Clinical studies that have evaluated the effect of SABA during long-term treatment with LABA in patients with COPD are lacking.

Previously, the effect of doubling doses of salbutamol (until a cumulative dose of $800 \mu \mathrm{g}$ ) given two hours after acute administration of different long-acting bronchodilators, such as formoterol, salmeterol, and oxitropium, was investigated in patients with COPD characterized by marked acute reversibility of airflow obstruction. ${ }^{7}$ In these circumstances, the maximal bronchodilating effect obtained at the highest dose of salbutamol was unchanged after a single dose of both LABA and oxitropium, as compared with baseline. However, both $\mathrm{FEV}_{1}$ and forced vital capacity showed a significant increase with administration of salbutamol following acute pretreatment with either LABA or oxitropium.

In the present study, these results were confirmed at least for formoterol also after eight hours, although to a lesser extent due to the half dose of the drug (12 $\mu \mathrm{g}$ versus $24 \mu \mathrm{g})$ and mainly due to the different phenotype of our COPD patients who had no significant reversibility of their airflow obstruction after acute inhalation of $400 \mu \mathrm{g}$ of salbutamol.

On the other hand, during chronic treatment with formoterol, further improvements of $\mathrm{FEV}_{1}$ and peak expiratory flow following administration of salbutamol were scarce and not significant either at 12 or 24 weeks of therapy, at least eight hours after LABA administration (Figure 1 and Table 2).

In contrast, the forced vital capacity increment after the highest cumulative dose of salbutamol was greater and still significant at 12 weeks and 24 weeks of therapy with formoterol. The aim of the study was to measure functional changes and not clinical improvement, and a similar trend was observed for inspiratory capacity in three tidally flow-limited and dynamically hyperinflated COPD patients at rest (Table 2).

Some speculation can be made regarding these findings. It is well known that peak expiratory flow and $\mathrm{FEV}_{1}$ changes are sensitive to a decrease in airflow resistance, mainly in the large and medium caliber airways, while the forced vital capacity changes reflect a diminution of air trapping (ie, plethysmographic residual volume) because of reduction of airflow resistance in the small airways and their closure at lower lung volumes. ${ }^{17}$ It is conceivable that formoterol inhaled as a dry powder may reach the central airways and rapidly saturate the $\beta_{2}$ receptors located in these airways. Therefore, after a few weeks of treatment with formoterol, the additional bronchodilating effect of salbutamol, as reflected by the peak expiratory flow and $\mathrm{FEV}_{1}$ changes, may be mild even at high doses. Conversely, the dry powder formulation of formoterol might have more difficulty in reaching the peripheral airways and occupy all $\beta_{2}$ receptors, ${ }^{18}$ leaving salbutamol given by metered dose inhaler as a possible means of further dilating and/or reopening these airways.

Such a possibility could be enhanced by the fact that even if $\beta_{2}$ adrenoreceptors are widely distributed in the bronchial tree, and their number increases in airway smooth muscle with increasing airway generation, showing higher density in smaller than in larger airways. ${ }^{19,20}$

Thus, the opportunity of further stimulating $\beta_{2}$ receptors in the peripheral airway smooth muscle cells may allow high doses of salbutamol inhaled by metered dose inhaler to substantially increase forced vital capacity (and decrease air trapping) by reducing expiratory airflow resistance at low lung volumes, even after many weeks of treatment with formoterol (Figure 1). Such reasoning may also explain the inspiratory capacity changes observed in three of our COPD patients, in whom baseline inspiratory capacity was markedly reduced because of dynamic pulmonary hyperinflation due to resting tidal expiratory flow limitation. ${ }^{5}$

The choice of focusing the effect on lung function following increasing doses of salbutamol on top of regular treatment with formoterol eight hours after its morning dose was based on the widely recognized fact that the bronchodilating effect of a pure $\beta_{2}$ agonist such as formoterol (when given alone) tends to decline after 8 hours (especially during chronic treatment). Therefore, this could be the best period to show a favorable effect of salbutamol. For the same reason, the need for COPD patients to use salbutamol as a rescue drug is expected to be more frequent in real life eight hours after a dose of formoterol.

The number of patients who completed the protocol was small. One third of patients dropped out for different reasons related to the length of the study. However, ten patients provided power of $80 \%$, at the $5 \%$ significance level, to detect the same smallest clinically relevant difference of $\mathrm{FEV}_{1}$ with the same standard deviation of difference in $\mathrm{FEV}_{1}$ after bronchodilators. Nevertheless, we recognize that these results need to be confirmed in larger cohorts of COPD patients. However, to the best of our knowledge, this is the first study that investigated the effect of SABA in terms of dose-response curve in stable COPD patients regularly treated with LABA for a long period, eventually using SABA to control sporadic acute symptoms or during mild worsening of their symptoms and not in presence of acute exacerbations. 
This was an observational study given that we could not include a group receiving placebo because of restrictions imposed by the local ethics committee arising from the duration of the study, but we believe that the reproducibility of $\mathrm{FEV}_{1}$ and forced vital capacity which this study assesses has been reported frequently enough to make this unnecessary. ${ }^{21}$

To our knowledge, no clinical and functional data have presently been reported about the effects of acute SABA administration on top of regular LABA treatment in COPD patients. In light of our results, we believe that a study with indacaterol, for instance, should be carefully performed.

In conclusion, the results of the present study suggest that during chronic therapy with conventional doses of formoterol (inhaled as a dry powder) in moderate-to-severe COPD, the addon use of salbutamol (by metered dose inhaler) does not improve peak expiratory flow and $\mathrm{FEV}_{1}$ markedly, but is still effective in reducing air trapping, as shown by the increase in forced vital capacity and possibly dynamic pulmonary hyperinflation in the presence of tidal expiratory flow limitation at rest. However, these effects that are expected to diminish acute symptoms in COPD patients during long-term treatment with LABA, can be obtained with doses of salbutamol (by metered dose inhaler) higher than $400 \mu \mathrm{g}$.

\section{Acknowledgment}

The authors acknowledge Mr Michele Guerini for his invaluable technical assistance with this work.

\section{Disclosure}

The authors report no conflicts of interest in this work.

\section{References}

1. Rabe KF, Hurd S, Anzueto A, et al. Global strategy for the diagnosis, management, and prevention of chronic obstructive pulmonary disease. GOLD Executive Summary. Am J Respir Crit Care Med. 2007;176: 532-555.

2. Chen AM, Bollmeier SG, Finnegan PM. Long-acting bronchodilator therapy for the treatment of chronic obstructive pulmonary disease. Ann Pharmacother. 2008;42:1832-1842.

3. Chapman KR, Bowie OM, Goldstein RS, et al. Guidelines for the assessment and management of chronic obstructive pulmonary disease. Canadian Thoracic Society Workshop Group. Can Med Assoc J. 1992; $147: 420-428$.
4. Appleton S, Poole P, Smith B, Veale A, Lasserson TJ, Chan MM. Long-acting beta2-agonists for poorly reversible chronic obstructive pulmonary disease. Cochrane Database Syst Rev. 2006;19:CD001104.

5. Tantucci C, Duguet A, Similowski T, Zelter M, Derenne JP, Milic-Emili J. Effect of salbutamol on dynamic hyperinflation in chronic obstructive pulmonary disease patients. Eur Respir J. 1998;12:799-804.

6. Postma DS, de Vries K, Koeter GH, Sluiter HJ. Independent influence of reversibility of airflow obstruction and nonspecific hyperreactivity on the long-term course of lung function in chronic airflow obstruction. Am Rev Respir Dis. 1986;134:276-280.

7. Cazzola M, Di Perna F, Noschese P, et al. Effects of formoterol, salmeterol or oxitropium bromide on airway responses to salbutamol in COPD. Eur Respir J. 1998;11:1337-1341.

8. Manning HL. Bronchodilator therapy in chronic obstructive pulmonary disease. Curr Opin Pulm Med. 2000;6:99-103.

9. American Thoracic Society. European Respiratory Society Task Force. Standardization of lung function testing. Eur Respir J. 2005;26: 319-338.

10. American Thoracic Society. European Respiratory Society Task Force. Interpretative strategies for lung function tests. Eur Respir J. 2005; 26:948-968.

11. Koulouris NG, Valta P, Lavoie A, et al. A simple method to detect expiratory flow limitation during spontaneous breathing. J Eur Respir J. 1995;8:306-313.

12. Tantucci C, Pinelli V, Cossi S, et al. Reference values and repeatability of inspiratory capacity for men and women aged 65-85. Respir Med. 2006;100:871-877.

13. Quanjer PH, Tammeling GJ, Cotes JE, et al. Lung volumes and forced ventilatory flows. Report working party standardization of lung function test. European community for steel and coal. Official statement of the european society. Eur Respir J Suppl. 1993;16:5-40.

14. Cazzola M, MacNee W, Martinez FJ, et al. ATS/ERS Task Force. Outcomes for COPD pharmacological trials: from lung function to biomarkers. Eur Respir J. 2008;31:416-468.

15. Gross NJ, Kerwin E, Levine B, et al. Nebulized formoterol fumarate: dose selection and pharmacokinetics. Pulm Pharmacol Ther. 2008; 21:818-823.

16. Steiropoulos P, Tzouvelekis A, Bouros D. Formoterol in the management of chronic obstructive pulmonary disease. Int J Chron Obstruct Pulmon Dis. 2008;3:205-215.

17. Cohen J, Postma DS, Vink-Klooster K, et al. FVC to slow inspiratory vital capacity ratio: a potential marker for small airways obstruction. Chest. 2007;132:1198-1203.

18. Hirst PH, Bacon RE, Pitcaim GR, Silvasti M, Newman SP. A comparison of the lung deposition of budesonide from Easyhaler, Turbuhaler and pMDI plus spacer in asthmatic patients. Respir Med. 2001;95:720-727.

19. Spina D, Rigby RJ, Paterson JW, Goldle RG. Autoradiographic localization of $\beta$-adrenoceptors in asthmatic human lung. Am Rev Respir Dis. 1989;140:1410-1415.

20. Hoffman EA, Chiplunkar R, Casale TB. CT scanning confirms beta receptor distribution is greater for small versus large airways. $\mathrm{Am} \mathrm{J}$ Respir Crit Care Med. 1997;155:Abstr 855.

21. Tweeddale PM, Alexander F, McHardy GJ. Short term variability in $\mathrm{FEV}_{1}$ and bronchodilator responsiveness in patients with obstructive ventilatory defects. Thorax. 1987;42:487-490.
International Journal of COPD

\section{Publish your work in this journal}

The International Journal of COPD is an international, peer-reviewed journal of therapeutics and pharmacology focusing on concise rapid reporting of clinical studies and reviews in COPD. Special focus is given to the pathophysiological processes underlying the disease, intervention programs, patient focused education, and self management protocols.

\section{Dovepress}

This journal is indexed on PubMed Central, MedLine and CAS. The manuscript management system is completely online and includes a very quick and fair peer-review system, which is all easy to use. Visit http://www.dovepress.com/testimonials.php to read real quotes from published authors. 